\title{
University-Industry Collaboration Through Engineering Final Year Project
}

\author{
${ }^{1}$ Ibrahim Alhamrouni, ${ }^{2}$ Mohammad Azannee Saad, ${ }^{3}$ Norida Kamarudin, ${ }^{4}$ Iskandar Hack \\ Universiti Kuala Lumpur British Malaysian Institute \\ Kuala Lumpur, Malaysia \\ 1ibrahim.mohamed@unikl.edu.my, ${ }^{2}$ azannee@unikl.edu.my, ${ }^{3}$ norida@unikl.edu.my, ${ }^{4}$ iskandar@unikl.edu.my
}

\begin{abstract}
Many studies within the area of engineering education and industrial partnership have highlighted the importance of university-industry collaboration. However, most studies have focused on making or strengthening the collaboration through research works between academicians and professionals that may have placed engineering students in less contributing position. This can lead to a significant amount of loss considering students' exposure to industry while in their academic years can provide them and future employers with greater benefits. In this paper, we discuss how engineering final year project (EFYP) undertaken by students can be employed to strengthen universityindustry collaboration and at the same time, comprehensively prepare students prior to joining the industry. Data for this study were responses obtained through semi-structured interview from two respondents selected through purposive sampling technique.
\end{abstract}

Keywords-engineering education; engineering final year project; university-industry collaboration

\section{INTRODUCTION}

Collaboration between engineering faculties and industry has been studied within the area of engineering education for over a century [1]. In fact, [2] suggested that the universityindustry collaboration has started in the 1800s. This has resulted in considerable amount of work highlighting the needs or relevance of establishing such collaboration between engineering faculties and industry [3]. With advancement in technology, the needs for the collaboration to be built and maintained is getting clearer and more essential [4].

Initially, the university-industry collaboration is often used as platform for industry to identify and train future employees [2]. However, the collaboration has since expanded as the global economies shifted to include other activities particularly research works [2]. What used to be government-funded research projects before are now being funded by industry with university's faculty members being responsible to carry out the research works. Outcomes from this collaboration are often manifested through commercialization of academic knowledge and technology sharing or transfer between these two organisations [5].

The benefits of such research collaboration between university and industry are wide-reaching [6]. [2] summarized them into three beneficiaries; social, university and industry. In general, university can enjoy wider source of fund to carry out particular research projects while the industry can use this opportunity to stimulate internal research activities and to increase company's reputation and provide competitive edge. This later benefits the society through enjoyment of innovative products or advanced technologies.

Within available literatures, many studies that highlighted the university-industry research collaboration are found to emphasize on research activities with involvement of faculty members and professionals from industry only. Even though such framework has proven to benefit both university and industry, it however contributes to limited exposure of engineering students to industry that could potentially provide them direct access to current engineering knowledge, issue and hands-on technology. As a result, students are left to mature in two separate worlds despite being highly relevant to each other; first is the university and the industry comes later.

Engineering students are important entities as they are the products prepared by engineering faculties for the industry. The needs to expose engineering students to industry while in their academic years have been regarded as highly important [7]. By having industrial experience integrated into their learning process, engineering students can acquire knowledge outside their conventional learning process that is mostly limited to lectures and lab activities [8]. Even though there are modules that place students within the context of industry such as industrial training, the period is usually short and does not directly put university-industry collaboration into the learning process.

However, the inclusion of engineering students into research activities between university-industry can potentially be achieved through engineering final year project (hereafter abbreviated as EFYP). Thus, current less advantageous scenario can be eliminated if EFYP is employed as one of the studentuniversity-industry bridging tools. EFYP is highly positioned within engineering curriculum [9]. As contrast to other courses that engineering students must attend, EFYP offers wider range of skills that is not limited to solely the acquisition of engineering knowledge [10]. Throughout the completion process, students can additionally develop other important skills such as writing (by writing the thesis), communication (through consultation with supervisor), time management and presentation of project (through defence or viva sessions). For these, EFYP has been regarded as important and carries heavier weightage of credit hour in the engineering syllabus. 
Upon completion of EFYP, successful students by right should acquire three general attributes imposed by an industry which are knowledge, skills and attitudes [11]. This is due to the nature of EFYP that is considered as open-ended research work that imposes great challenge to students albeit under supervisor's guidance [12]. Students are exposed to independent learning where they are required to have regular consultation with appointed supervisor from the faculty discussing the project. They will have to complete the agreed project in assigned timeline and during the completion process, they consult, present and write the idea in proper report. For this, EFYP can be seen as one of the mechanisms for students to develop non-engineering skills while acquiring in-depth engineering knowledge.

The present study has the objective of positioning EFYP as one mechanism to strengthen the university-industry collaboration and at the same time, prepare students to becoming comprehensive graduates for industrial needs. Specifically, this study attempts to provide suggestions on how engineering curriculum can be made relevant to the industry in the aspect of university-industry collaboration and acquisition of nonengineering skills for the benefits of future employers within the small context of EFYP.

\section{METHOD}

\section{A. Research design and instrument}

The present study is designed as qualitative study which is seen through data collection technique, analytical approach and presentation of findings. The study obtained its findings through interview protocol conducted to two respondents which details are given in the following section (section B).

Interview was designed and conducted as semi-structured interview. Questions for the interview were developed through problem statements and findings reported from relevant literatures. As a result, a total of 12 primary questions were being used as research instruments in gathering the data. Secondary questions on the other hand were developed during the interview sessions using responses provided by the respondents. For example, such questions were initiated when researcher (or interviewer) requested for specific information, examples or clarification.

Interviews were audio recorded using proper recording tool in a quiet office room and later were orthographically transcribed. However, answering the interview questions through email exchanges between respondents and researcher was also permitted due to unavailability of respondents for faceto-face interview.

\section{B. Respondents}

Purposive sampling technique was used to select the study's respondents. This allows the study to have specific requirements for selection of respondents. Requirements for inclusion into the study as respondents include experience working in the industry and university for more than 10 years combined and active collaboration with the industry while working in university that is measured through amount of grants received, active industrialmanship or where possible, wider social network. This resulted in two respondents to participate in the interviews that later, the responses obtained served as the study's primary data source.

First respondent (pseudonym respondent 1) is an American associate professor who has experienced working in the United States (hereafter US) that includes US Department of Defense and University of Purdue's Electrical Engineering Technology Department. He had worked as project manager and quality control engineer before moving to academic world in both US and Malaysia and has hold various positions such as department chair and adjunct professor. He has more than 30-year experience in both the industry and university that includes current university he is attached to.

Second respondent (pseudonym respondent 2) is an associate professor who is also a certified engineer. He had experience of 10 years in the industry within the area of testing, maintenance and consultation before moving into education. At university where he currently serves for more than seven years, he has hold position such as department's head and other assigned managerial tasks in addition to teaching at both undergraduate and postgraduate levels and supervising various research projects.

Table 1 below summarizes the background of selected respondents.

TABLE I. RESPONDENTS’ PROFILES

\begin{tabular}{|l|c|c|}
\hline & Respondent 1 & Respondent 2 \\
\hline Nationality & American & Malaysian \\
\hline Age & $60+$ years old & $40+$ years old \\
\hline Current position & Associate Professor & Associate Professor \\
\hline Professional title & - & Ir. \\
\hline $\begin{array}{l}\text { Experience in } \\
\text { industry }\end{array}$ & $10+$ years & $10+$ years \\
\hline $\begin{array}{l}\text { Experience in } \\
\text { university } \\
\text { (Academic) }\end{array}$ & $30+$ years & $7+$ years \\
\hline
\end{tabular}

\section{Data Analysis}

Recorded interviews were first orthographically transcribed for analysis purpose. This step was not performed for respondents who answered interview questions through email exchanges as the answers were already in static format.

The next step of analysis was to highlight specific key words based on the responses provided by respondents. This highlighting is similar to coding technique often used in analyzing interview transcript. However, due to limited number of literatures that could provide specific framework for coding of responses, highlighting key words used by respondents that linked to research objectives is sufficient given the context of study.

\section{Validity}

Issue of validity in this study concerns the selection of respondents, questions asked during interview and formulated findings based on the responses.

Selection of respondents to be interviewed strictly follows purposive sampling technique where respondents must meet specific criteria before being included as respondents. The criteria as explained in section B (respondents) were examined 
from respondents' profiles that are available on university's website.

Second, questions being asked during the interview protocol are developed based on literature review performed by researchers. Questions are then linked to research objectives this study has had and later, cross-checked for suitability and accuracy among researchers. This resulted in 12 primary questions as the study's instruments. Finally, as this study does not develop specific coding technique for interview transcript, the findings are given using the respondents' actual responses with no or minimal changes made by the researchers.

\section{E. Research Ethics}

Once respondents have been identified, their permissions were required before interview can be conducted. Written permission through the form of e-mail was obtained before interview was put in session. In order to guard confidentiality of respondents, specific pseudonym was assigned to both respondents. Respondents were also explained on the study's nature; its objectives, data collection technique and expected findings before participating in the interview.

\section{FINDINGS}

The findings are discussed in the following sub-sections. The first section provides findings on the importance of engineering education to be linked to industry. The second section focuses on the role of EFYP in bringing engineering education closer to industrial needs while the third section discusses how EFYP can be manipulated as tool for students to develop non-engineering skills. The italic words in the following sections represent actual words used by respondents in the interview.

\section{A. Engineering education and industry}

Among the questions asked to both respondents are on the importance of linking engineering education to the industry. First question specifically initiated respondents to determine the level of importance to link engineering education to the industry. For this, both respondents agreed that tailoring engineering education to the requirements of industry is "vital" (respondent 1) and "very important and vital" (respondent 2). The reasons for these responses are first employability of graduates and second, making higher education relevant to future development and mankind.

Another respond initiated from both respondents is strategies that can be used to close gap between university and industry. Respondent 1 suggested university to welcome industrial professional i.e. engineer to teach at engineering faculty as parttime instructor. This can allow students to listen to someone who actually experiences the industry. In addition, industry can come on board by providing actual industrial projects that the company intends to use in their company as university's final year project. For example, students' engineering projects are made based on the industry's suggestion so the outcomes from such projects can be extended. On the other hand, respondent 2 suggested extensive industrial visit from students to companies and also industrial incubators to be placed within university's compound or laboratory.
Finally, the respondents are asked on what are the challenges to link engineering education to industry. Both of them answer within the context of Malaysia with comparison being made to situation in the US (respondent 1). The first challenge as given by first respondent concerns funding. In the US, "industry is rewarded with tax incentives for any donations to universities". This strategy can motivate companies to invest their money on academic works and certainly increase the research collaboration between university and industry as the donation can function as source of research's funding. Another challenge given by first respondent is the limitations placed on the universities by the accreditation bodies. According to him, "there appears to (be) a conflict between what industry wants and what BEM/EAC feels should be in programs". The respondent suggested that the former should be the driving force in engineering program than the later. He also suggested that agreements such as Washington Accord are good but should not be used as the primary source in determining program as the engineering program should be designed according to the needs of the society such as agricultural engineering to be widely offered in Nebraska. This relates to the relevancy of universal rules to specific societal needs.

On the other hand, second respondent said that consistency in interaction between university and industry is lacking. He suggested for this area to be improved through various activities such as industrial visits or university visits that can benefit both organisations.

\section{B. EFYP as one of the university-industry briding tools}

The primary objective of this study is to see how EFYP can make engineering education relevant to industry and at the same time, prepare students to undertake challenges in the real industry life.

First question asked to both respondents is how EFYP can be made relevant to industry. Respondent 1 said, "industry should be providing projects and be active in evaluating students' works". This is in agreement with second respondent that suggested "enhanced industry-university supervisor interaction (in agreed project)". In details, this suggestion suggested projects that could either be current active projects which industry would like to have additional people working on or students' projects that may have not been thought by the industry. Through this method, "both the students and industry benefit from this arrangement; the students are working on real projects similar to what they would see when they graduate and industry often get ideas from the students that the engineers did not come up with". However, this strategy must be agreed by the industry's engineers in the aspect of working with students on what projects.

Another question seeks responses from both respondents on the needs of having EFYP examiner from the industry. Both respondents agreed and said "it is critical to have input from industry" (respondent 1) and "yes definitely" (respondent 2). Both agreed that having EFYP examiner from the industry can complement the university-industry collaboration by having them attending presentation sessions and providing inputs to make sure students' projects are aligned with current engineering trends. 
The previous question is further explored on whether it is a good idea to have students' EFYP projects being supervised by professional from the industry. Respondent 1 said that it is " $a$ very difficult area" due to differences in evaluation techniques employed by professional and university's lecturer. However, it is good to include professional in supervision especially when there is project that is sponsored by the industry. This example is referred to common practice by the universities in US. Respondent 2 provided similar answer where differences in work expectation may cause difficulty within the area of assessment.

In summary, EFYP can increase the collaboration between university and industry through having common projects to be undertaken by the engineering students. Both faculty member and professional engineer will come together on board and help students during the process. In addition to acquiring theoretical knowledge from the faculty members, students can be exposed to current practices in real engineering world from the professional engineer. The university and industry can also benefit through the commercialization of projects' outcomes and exchange of expertise.

\section{EFYP as tool to develop non-engineering skills}

The second objective of this study is to evaluate how EFYP can help students to obtain non-engineering skills that will benefit the industry.

The first question that was asked to both respondents was derived from problem is often seen during EFYP process where the focus is entirely on the engineering work. The respondents were asked how such non-engineering skills be made aware and later emphasised by both supervisor and students during the process of completing EFYP.

Respondent 1 said, there is difference in student getting involved in industrial sponsored projects than students working on their own at university level. The difference is seen because the former type has to meet the real need from company and produce periodic progress reports, regular design reviews, attend discussion with real professional and get themselves familiar with professional process such as getting approval for changes in project. This rewarding experience may not be enjoyed by students working on their own. According to respondent 1, "to be honest, I have not found or seen a way to completely provide the same experience for students that are working on projects of their own (than the industrial sponsored projects)".

In addition to exposing students to working with professional from industry, clearer assessment rubric and evaluation methods that manage to capture the intended learning outcome that is not necessarily on the acquisition of engineering knowledge must be made available (respondent 2). Students must be exposed or informed by their supervisor to various assessment criteria from the start of programme to make them aware.

The next part is to seek agreement from both respondents on the role of EFYP in developing students' non-engineering skills in addition to engineering knowledge. Both respondents agreed on the crucial role EFYP has on getting students to becoming comprehensive or industry-satisfied engineers. When asked how these skills can be developed while completing EFYP, both respondents agreed that this should be exposed at the early years of engineering programme and not necessarily at EFYP stage.

Both respondents also agreed that having these soft skills such as giving presentations and producing technical writings are very important in engineer's career and can result in differences in the aspect of career advancement and salary range.

In summary, it is not necessarily for EFYP to be the only tool to develop non-engineering skills but both respondents agreed that EFYP provide continuous platform for students to develop such skills. The nature of project and clearer assessment checklist will help to stimulate the skills and visualize the intended outcomes.

\section{DISCUSSION}

The present study has explored how EFYP can be manipulated to becoming a tool to first, bridge universityindustry collaboration and second, to help students develop necessity skills for the benefit of their future employment and employers.

Taking the framework of research collaboration between university's faculty members and professional from industry, the present study focuses on the small context of EFYP and how EFYP be used to increase university-industry collaboration. The benefits of such practice can be enjoyed by all parties involved in the process; student, university and industry [8]. Students can experience working with real engineer from the industry and get themselves familiar to working style in the industry prior to joining such world. Professional from the industry on the other hand can work along with faculty members in providing engineering knowledge that is current and aligned with requirements from the industry. In addition, the outcomes from industrial-relevant EFYP can be taken to next stage such as integration with current technology or commercialization of knowledge or products.

The other role that EFYP can contribute is by helping students to develop skills that will be beneficial for their employments and employers they will be working for. Students will have to undergo processes to complete EFYP such as presenting the idea, preparing lab reports and meeting with supervisors [10]. With the inclusion of professional from the industry, the formality in working increases and students can be exposed to real working style where in addition to reporting to their supervisors, they also have to report to the professional engineer. This can greatly help them to acquire other skills other than engineering knowledge that can reduce current frustration of employers on quality of current engineering graduates [13].

\section{CONCLUSION}

The role of EFYP has been explored in the present study in relation to how it can help to increase research collaboration between university and industry. In addition, how students can develop non-engineering skills such as presentation skill, communication skill, time management and writing is also discussed. 
Data were obtained from two respondents through semistructured interview consisting of 12 primary questions. Respondents were selected to be interviewed through purposive sampling technique to ensure the validity of data. From analysis of responses conducted, having professional from the industry can greatly enhance research collaboration between university and industry. In addition, students can also be exposed to current technology as reported by industrial professional who has the first real-experience. In addition, EFYP can also assist students to develop their non-engineering skills that will benefit themselves prior to joining professional world and also provide advantage to employers in having well-rounded engineers working for them. But it should be noted that EFYP is merely a continuous platform for students to develop such skills as the skills should be nurtured since the beginning of an engineering programme.

In conclusion, this study recommends future intended study within similar area of interest to include respondents from the industry to be interviewed and compare their responses to those provided by faculty members. Collecting data through actual practice (i.e. having industry and university working together for students' EFYP for a specific experimental period) can also increase the credibility of findings.

\section{ACKNOWLEDMENT}

Great acknowledgments are due to respondents of this study who have provided the study with its primary data source. Thanks are also due to editors or anonymous reviewers who have spent time improving the quality of this paper.

\section{REFERENCES}

[1] G. Edmondson, L. Valigra, M. Kenward, R. L. Hudson and H. Belfield, "Making Industry-University Partnerships Work," Science Business Innovation Board AISBL, 2012

[2] M. Perkmann, V. Tartari, M. McKelvey, E. Autio, A. Brostrom, P.D'Este, R. Fini, A. Geuna, R. Grimaldi, A. Hughes, S. Krabel, M. Kitson, P.
Llerena, F. Lissoni, A. Saletr and M. Sobrero, "Academic Engagement and Commercialization: A Review of the Literature on UniversityIndustry Relations," Research Policy, vol. 42, pp. 423-442, 2013

[3] R. Stephens, "Aligning Engineering Education and Experience to Meet the Needs of Industry and Society," The Bridge, vol. 43, no. 2, pp. 31-34, 2013

[4] L. Manzione and A. Abu-aisheh (2011). Preparing Engineering Students for the Global Sourcing Environment [Online]. Available: https://www.asee.org/documents/sections/northeast/2011/PREPARINGENGINEERING-STUDENTS-FOR-THE.pdf

[5] E. May and D. S. Strong, "Is Engineering Education Delivering What Industry Requires?," in 2006 Proceeding of the Canadian Engineering Education Association, pp. 204-212

[6] J. Guimon (2013). Promoting University-Industry Collaboration in Devloping Countries [Online]. Available: http://innovationpolicyplatform.org/sites/default/files/rdf_imported_doc uments/PromotingUniversityIndustryCollaborationInDevelopingCountri es.pdf

[7] N. R. Mead, "Industry/University Collaboration in Software Engineering Education: Refreshing and Retuning Our Strategies," in 2015 IEEE/ACM 37th IEEE International Conference on Software Engineering.

[8] Rajibussalim, T. Sahama and H. Pillay, "Realisation of universityindustry collaboration through industry-based learning at Indonesian higher education," in 2016 International Technology, Education and Development Conference, pp. 3853-3863

[9] J. Uziak, "Position of the final year project in an engineering curriculum," Global Journal of Engineering Education, vol. 17, no. 3, pp. 113-118, 2015

[10] A. Shafie, J. B. Janier and R. Herdiana, "Students' Learning Experience on the Final Year Project for Electrical and Electronics Engineering of Universiti Teknologi PETRONAS," in 2008 International Conference on Engineering Education

[11] R. A. Gamboa and S. Namasivayam, "Quantitative Measurement of Taylor's Graduate Capabilities for Engineering Programmes," in Proceeding of 2013 Taylor's $6^{\text {th }}$ Teaching and Learning Conference: Transformative Higher Education Teaching and Learning in Practice, pp. $72-81$

[12] D. T. K. Tien and S. C. Lim, "Assessment and Feedback in Final-Year Engineering Project" in Assessment for Learning and Beyond Classroom. Singapore: Springer, 2016, ch. 4, pp. 125-136

[13] H. Atkinson and M. Pennington, "Unemployment of engineering graduates: the key issues," Engineering Education, vol. 7, no. 2, pp. 7-15, 2012 